\title{
ACEITE DE OLIVA VIRGEN Y DENOMINACIONES DE ORIGEN PROTEGIDAS: ANÁLISIS DESCRIPTIVO DEL CASO ANDALUZ
}

\author{
$\left.\underline{\text { Ana García Moral }}{ }^{a},{ }^{*}\right), \underline{\text { Leticia Gallego Valero }}{ }^{a}, \underline{\text { Encarnación Moral Pajares }}^{a}$,
}

aUniversidad de Jaén (Jaén, agm00037@red.ujaen.es, lgallego@ujaen.es,emoral@ujaen.es)

\section{Resumen}

Las Denominaciones de Origen Protegidas (DOP) reguladas por la normativa de la UE, tienen como objetivo proporcionar información solvente a los consumidores sobre la calidad de los productos, vinculada al origen de los mismos. Esto, a su vez, puede favorecer la actividad comercial de los productores y estimular procesos de desarrollo rural, como defiende la legislación comunitaria. A partir de los argumentos que proporciona la literatura revisada y la información que ofrece el Ministerio de Agricultura, Pesca y Alimentación (MAPA), en este documento se analiza, en primer lugar, el peso de la producción con DOP en el sector oleícola andaluz, responsable del 81,49\% del total del aceite de oliva virgen obtenido en España en 2018. En segundo lugar, se investiga su protagonismo en el total de producción agroalimentaria certificada en el conjunto del Estado y, por último, se trata su orientación exportadora. La evidencia constata que, en conjunto, el aceite de oliva virgen con DOP andaluz es residual, lo que justifica que el sector no aprovecha adecuadamente las potencialidades que ofrece la producción certificada en el desarrollo de una estrategia de comercialización.

Palabras clave: Aceite de oliva virgen (AOV), Denominación de Origen Protegida (DOP), Andalucía, exportación.

\section{Introducción y objetivos}

La Denominacion de Origen Protegida (DOP), como toda indicacion geográfica ${ }^{13}$, reconoce una mercancía como procedente de un territorio en particular y, basándose en su origen, los consumidores pueden asociar un producto con una calidad, característica o reputación determinadas. Por la información que trasmiten las DOPs son atributos diferenciadores de los bienes en el mercado, pudiendo ser elementos determinantes en el desarrollo de una marca vinculada a su pocedencia. Existen diversos estudios que indican que, en condiciones adecuadas, estas indicaciones pueden contribuir al desarrollo de las zonas rurales [véase Bowen (2010) y Cei et al. (2018)], aunque no siempre [véase Neilson et al. (2018)], y favorecer la venta de los productos locales en los mercados nacionales e internacionales [véase Bryla (2015), Galati et al. (2017) y Lubinga en al. (2020)]. El derecho a utilizar una indicación geográfica generalmente recae en los productores regionales y el valor agregado generado por aquella se acumula en los productores del lugar. Además, ayuda a poteger los conocimientos tradicionales transmitidos de generación en generación por la comunidad de una región en particular y suelen generar importantes beneficios secundarios en las áreas del turismo y la gastronomía [véase Marcoz et al. (2016) y Fusté-Forné (2020)].

La Unión Europea cuenta con indicaciones geográficas y denominaciones geográficas protegidas distribuidas desigualmente por tipos de producto y país. Según un estudio publicado por la Comisión Europea en 2020 el valor de la produción de mercancías agricolas y almentarias certificadas es como media el doble del que registran las ventas de produtos similares sin esta certificación.

Los objetivos de esta investigación son, en primer lugar, conocer el peso de la producción con DOP en el sector oleícola andaluz. En segundo lugar, concretar su protagonismo en el total de producción oleícola con DOP en el conjunto del Estado. En tercer lugar, analizar si el valor medio por kilogramo de aceite de oliva virgen (AOV) con DOP es superior al que presenta el aceite de oliva virgen extra (AOVE) en genral y, por último, investigar la orientación exportadora de esta industria agroalimentaria.

A partir de los argumentos expuestos y la literatura revisada las hipótesis a contrastar son las siguientes:

H 1. El sector oleícola andaluz, responsable del $80 \%$ de la producción de AOV del conjunto del Estado, presenta una elevada especialización productiva en AOV con DOP.

$\mathrm{H}$ 2. El valor medio por kilogramo del AOV con DOP comercializado es superior al que registra el producto no certificado.

H 3 El AOV con DOP producido en Andalucía mantiene una actividad exportadora más dinámica que la protagonizada por la industria andaluza que comercializa AOV.

\section{Metodología}

\footnotetext{
${ }^{13}$ De acuerdo con el recoge el Reglamento (UE) no 1151/2012 del Parlamento y del Consejo, de 21 de noviembre de 2012, sobre los orígenes de calidad de los productos agrícolas y alimenticios.
} 
El estudio empírico que fundamenta esta investigación se desarrolla a partir de la información secundaria procedente de diferentes de instituciones nacionales como son el Ministerio de Agricultura Pesca y Alimentación (MAPA) y la Agencia Estatal de Administración Tributaria. El período temporal de análisi viene determinado por la disponibilidad de datos sobre las variables: producción y exportación de AOV con DOP en Andalucía y España. Desde 2008 y hasta 2019 la Subdirección de Calidad Diferenciada y Agricultura Ecológica del Ministerio de Agricultura Pesca y Alimentación en colaboración con los Consejos Reguladores de Denominaciones de Origen Protegidas e Indicaciones Geográficas Protegidas y entidades asimiladas elaboran el informe: "Datos de las Denominaciones de Origen Protegidas (DOP) e Indicaciones Geográficas Protegidas (IGP) de Productos Agroalimentarios". En el caso del AOV producido en la región andaluza no existe ninguna IGP ${ }^{14}$ con producción durante el periodo temporal considerado, por lo que el estudio se centra en la actividad productiva y comercial de las DOPs. Por otro lado, conviene tener en cuenta que la información que ofrece la Subdirección de Calidad Diferenciada y Agricultura Ecológica se refieren a las distintas DOPs, no agregando por regiones o provincias. Para disponer de datos referidos al conjunto de la región andaluza se ha considerado la suma de los valores imputables a cada una de las DOPs que operan en el territorio andaluz en cada ejercicio económico, que reportan información al Ministerio cada año. En 2008 las DOPs de Andalucián operativas suman 11, un 40,4\% del total (Baena, Campiña de Jaén, Estepa, Montes de Granada, Montoro-Adamuz, Poniente de Granada, Priego de Córdoba, Sierra de Cádiz, Sierra de Cazorla, Sierra de Segura y Sierra Mágina). En 2009 se une la DOP Antequera, en 2010 desaparece Campiña de Jaén y en 2011 la DOP Lucena ofrece sus primeros datos, siendo 12 las que operan en 2019, 41,38\% del total. Por último, señalar que se ha considerado el valor de la producción certificada cada año en la que se incluye hasta 2015 sólo AOVE y AOVE y AOV en los años que van de 2016 a 2019.

\section{Resultados}

Andalucía es origen del 78,12\% del AOV con DOP obtenido en España en el conjunto del perído analizado, lo que se corresponde con su protagonismo como primera zona oferente de este producto agroalimentario en el territorio nacional. La región, sin embargo, no presenta un indice de especialización en la producción de AOV con DOP superior a 100, especialmente en los últimos años, lo que justifica, en parte, que la calidad no sea una variable fundamental en la estrategia productiva y comercial del sector.

Gráfico 1. Participación de Andalucía en la producción de AOV con DOP y en la producción de AOV de España (2008-2019).

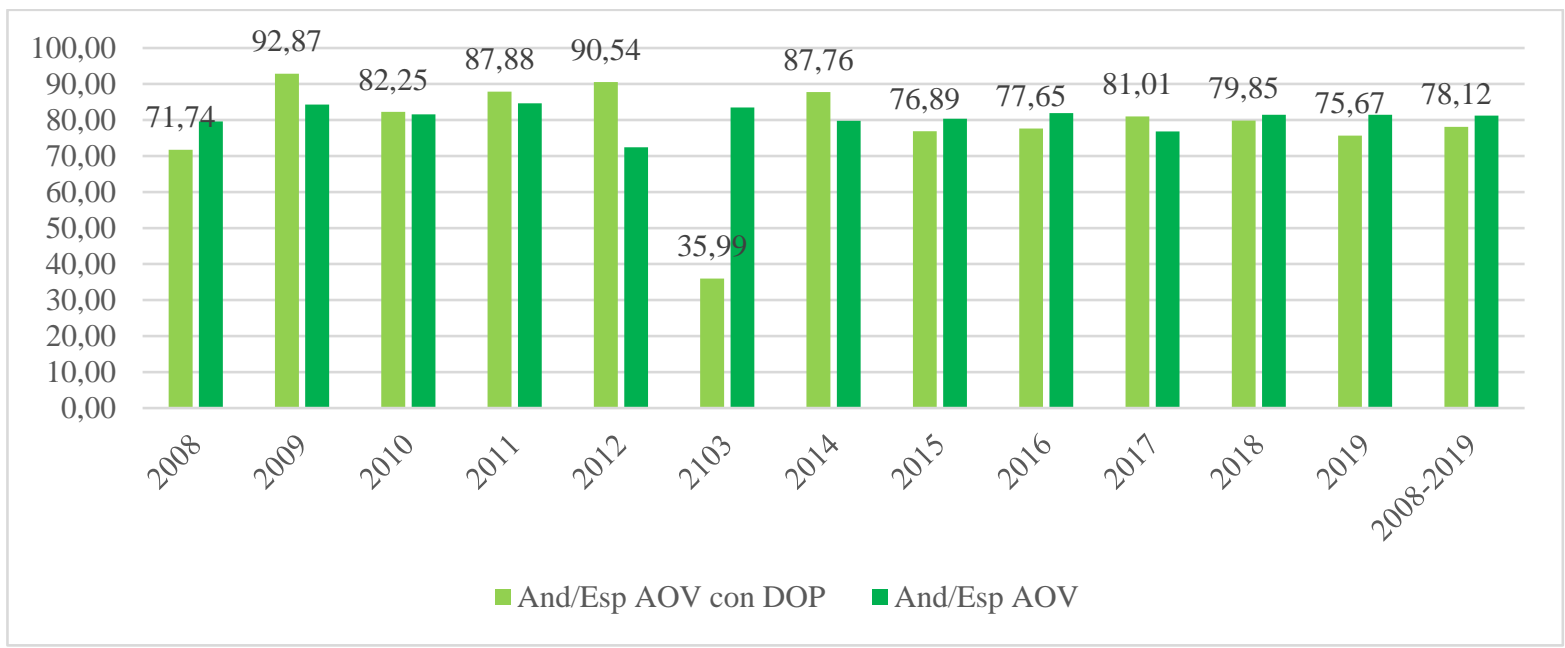

Fuente: MAPA.

Cuadro 1. Peso del AOV con DOP en la producción de AOV de Andalucía y España e Índice de especialización en la producción de AOV con DOP en Andalucía (IE)

\begin{tabular}{|l|l|l|l|l|l|l|l|l|l|l|l|l|l|}
\hline & 2008 & 2009 & 2010 & 2011 & 2012 & 2103 & 2014 & 2015 & 2016 & 2017 & 2018 & 2019 & $\begin{array}{l}2008- \\
2019\end{array}$ \\
\hline Andaluía & 4,19 & 6,68 & 7,23 & 8,26 & 26,06 & 3,25 & 18,92 & 4,95 & 6,69 & 7,07 & 4,33 & 8,36 & 7,44 \\
\hline España & 4,65 & 6,06 & 7,17 & 7,95 & 20,84 & 7,53 & 17,20 & 5,18 & 7,06 & 6,71 & 4,42 & 9,00 & 7,74 \\
\hline IE & 90,10 & 110,16 & 100,83 & 103,85 & 125,04 & 43,10 & 110,01 & 95,71 & 94,77 & 105,43 & 97,99 & 92,86 & 96,15 \\
\hline
\end{tabular}

Fuente: MAPA.

\footnotetext{
${ }^{14}$ El 5/05/2020 se inscribe en el Registro comunitario la IGP aceites de Jaén.
} 
En todos y cada uno de los año para los que se dispone información y es posible poder calcular tanto el valor medio por kilogramo del AOV con DOP comercializado por compañías andaluzas, como para el conjunto del Estado, se confirma el mayor valor de esta grasa vegetal, frente al que presenta el AOVE, según el anuario estadístico del MAPA.

Gráfico 2. Valor medio por kilogramo de AOV con DOP de Andalucía y España y valor medio por kilogramo del AOVE de España (2008-2019).

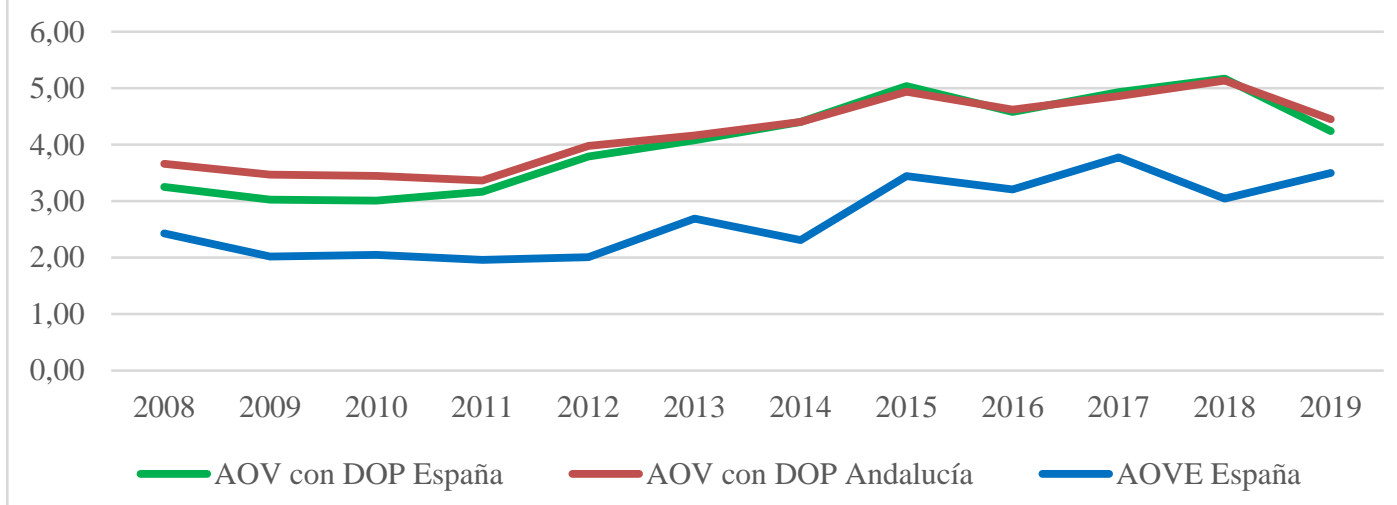

Fuente: MAPA.

El AOV con DOP en Andalucía y en el conjunto de España tiene como destino prioritario el mercado nacional (ver cuadro 2). Sin embargo, la actividad exportadora que ha desarrollado este subsector oleícola andaluz entre 2008 y 2019 es muy intensa, registrando sus ventas en el mercado internacional una tasa media de crecimiento anual acumulado del 9,27\%, muy superios a la imputable a las exportaciones de AOV de Andalucía y de España que son de un 5,89 y un 4,80\%, respectivamente.

Cuadro 2. Porcentaje de AOV con DOP comercializado en los mercados internacionales en España y Andalucía (2008-2019)

\begin{tabular}{|l|l|l|l|l|l|l|l|l|l|l|l|l|}
\hline & 2008 & 2009 & 2010 & 2011 & 2012 & 2013 & 2014 & 2015 & 2016 & 2017 & 2018 & 2019 \\
\hline España & 12,29 & 13,21 & 16,32 & 28,41 & 24,51 & 25,50 & 28,04 & 26,87 & 24,20 & 24,47 & 20,55 & 26,19 \\
\hline Andalucía & 14,72 & 17,28 & 21,45 & 21,81 & 23,43 & 29,35 & 24,23 & 34,42 & 33,99 & 33,74 & 30,26 & 32,52 \\
\hline
\end{tabular}

Fuente: MAPA.

\section{Conclusiones}

El análisis realizad ha permitido rechazar la primera hipótesis planteada y confirmar la segunda y tercera. Por tanto, es posible afirmar lo siguiente:

1. Andalucía, la primera zona productora de AOV de España, no presenta una clara especialización productiva en AOV con DOP. Esta producción sólo asciende a 63.211,47 toneladas en 2018, un 4,33\% del total del AOV andaluz.

2. El mercado retribuye la calidad del producto con DOP, el precio que se paga por kilogramo para esta mercancía es superior al precio medio imputable al AOV, en general .

3. La industria agroalimentaria que produce AOV con DOP presenta una propensión a exportar menor que el conjunto del sector oleícola: No obstante, la dinámica de sus ventas internacionales durante la última década ha sido muy intensa, superior a la que registra la industria de AOV, en conjunto.

A partir de los resultados derivados nos planteamos avanzar en la investigación para poder responder a cuetiones como las siguientes y que serán tratadas en futuros trabajos: ¿qué factores condicionan el desarrollo de esta industria por el lado de la oferta?, ¿qué variables pueden explicar la diferencia en los precios del AOV con DOP producido en España?, ¿la variedad de la aceituna empleada para producir AOV con DOP determina el precio por kiligramo de AOV vendido? ¿qué mercado internacionales son en los que se concentran las ventas de AOV con DOP español?, ¿cuál ha sido la dinámica exportadora de las distintas territorios que exportan AOV?, ¿qué factores influyen en esta dinámica?, etc.

Bibliografía

Bryła, P. (2015). "The role of appeals to tradition in origin food marketing. A survey among Polish consumers". Appetite, 91: 302-310.

Bowen, S. (2010). "Embedding local places in global spaces: Geographical indications as a territorial development strategy". Rural Sociology, 75 (2): 209-243. 
Cei, L., Stefani, G., Defrancesco, E., \& Lombardi, G. V. (2018). "Geographical indications: A first assessment of the impact on rural development in Italian NUTS3 regions". Land Use Policy, 75: 620-630.

Fusté-Forné, F. (2020). "Developing cheese tourism: a local-based perspective from Valle de Roncal (Navarra, Spain)". Journal of Ethnic Foods, 7 (1): 1-9.

Galati, A., Crescimanno, M., Abbruzzo, A., Chironi, S., \& Tinervia, S. (2017). "The premium price for Italian red wines in new world wine consuming countries: the case of the Russian market”. Journal of Wine Research, 28 (3): 181-193.

Lubinga, M. H., Ngqangweni, S., Van der Walt, S., Potelwa, Y., Nyhodo, B., Phaleng, L., \& Ntshangase, T. (2020). "Geographical indications in the wine industry: does it matter for South Africa?" International Journal of Wine Business Research, 33 (1): 47-59.

Marcoz, E. M., Melewar, T. C., \& Dennis, C. (2016). "The value of region of origin, producer and protected designation of origin label for visitors and locals: the case of fontina cheese in Italy". International Journal of Tourism Research, 18 (3): 236-250.

Neilson, J., Wright, J., \& Aklimawati, L. (2018). "Geographical indications and value capture in the Indonesia coffee sector”. Journal of Rural Studies, 59: 35-48 